\title{
The Water - Antipyrine - Alkyl Benzene Sulfonic Acid Stratifying System to Extract Metal Ions
}

\author{
Svetlana A. Zabolotnykha, \\ Valeria O. Zhelnina ${ }^{\mathrm{b}}$, Svetlana A. Denisova ${ }^{\mathrm{b}}$, \\ Alexander M. Elokhov ${ }^{\mathrm{b}}$ and Andrey E. Lesnov ${ }^{\mathrm{a}, \mathrm{c}}$ \\ a"Institute of Technical Chemistry of Ural Branch of the RAS" \\ 3 Korolev Str., Perm, 614013, Russia \\ ${ }^{b}$ Perm State National Research University \\ 15 Bukirev Str., Perm, 614600, Russia \\ 'Perm State Agricultural Academy \\ 23 Petropavlovskaya Str., Perm, 614990, Russia
}

Received 20.09.2017, received in revised form 20.10.2017, accepted 17.11.2017

The boundary of the two-phase liquid equilibrium area in an aqueous self-stratifying and protolytically interacting system based on alkyl benzene sulfonic acid (ABSA) and antipyrine (Ant) was determined by isothermal titration at $(23 \pm 2){ }^{\circ} \mathrm{C}$. The potentiometric method was used to determine the dissociation constant of alkyl benzene sulfonic acid. The optimum concentration parameters of the extraction process in the system under investigation were determined. The aliquation stability and the phase volume ratio as dependent on inorganic acids (hydrochloric, sulfuric) and ammonium thiocyanate were studied. With addition of up to $2.5 \mathrm{~mol} / \mathrm{l}$ of $\mathrm{HCl}, 2.0 \mathrm{~mol} / \mathrm{l}$ of $\mathrm{H}_{2} \mathrm{SO}_{4}$ and $0.3 \mathrm{~mol} / \mathrm{l}$ of $\mathrm{NH}_{4} \mathrm{SCN}$, the two-phase liquid equilibrium area is maintained. Interfacial distribution of Sc(III), La(III), Ga(III), $\mathrm{Fe}(\mathrm{III}), \mathrm{Tl}(\mathrm{III})$ and $\mathrm{Cu}(\mathrm{I})$ in the $\mathrm{H} 2 \mathrm{O}$ - Ant - ABSA system from hydrochloric solutions was studied. Conditions for quantitative extraction of iron, scandium and thallium are found. Exploration of extraction of $\mathrm{Fe}(I I I), \mathrm{Zn}(\mathrm{II}), \mathrm{Co}(\mathrm{II}), \mathrm{Cu}(\mathrm{II})$ and $\mathrm{Cd}(\mathrm{II})$ from thiocyanate solutions enable ascertaining optimal conditions for quantitative extraction of zinc, copper and iron.

Keywords: alkyl benzene sulfonic acid, antipyrine, extraction, thiocyanates.

DOI: $10.17516 / 1998-2836-0047$.

(c) Siberian Federal University. All rights reserved

* Corresponding author E-mail address: zabolotsveta@mail.ru 


\title{
Использование расслаивающейся системы \\ вода - антипирин - алкилбензолсульфокислота \\ для экстракции ионов металлов
}

\author{
С.А. Заболотных ${ }^{a}$, В.О. Желнина ${ }^{0}$, \\ С.А. Денисова ${ }^{\sigma}$, А.М. Елохов ${ }^{\sigma}$, А.Е. Леснов ${ }^{\text {a,в }}$ \\ ${ }^{a}$ Институт технической химии Уральского отделения РАН \\ Россия, 614013, Пермь, ул. Королева, 3 \\ ${ }^{\sigma}$ Пермский государственный \\ национальный исследовательский университет \\ Россия, 614600, Пермь, ул. Букирева, 15 \\ ${ }^{8}$ Пермская государственная сельскохозяйственная академия \\ Россия, 614990, Пермь, ул. Петропавловская, 23
}

\begin{abstract}
Методом изотермического титрования при $(23 \pm 2){ }^{\circ}$ С определена граница области двухфазного жидкого равновесия в водной расслаивающейся системе с протолитическим взаимодействием на основе алкилбензолсульфокислоты (АБСК) и антипирина (Ант). Потенциометрическим методом определена константа диссоциации алкилбензолсульфокислоты. Найдень оптимальные кониентрационные параметры процесса экстракциии в исследованной системе. Изучено влияние неорганических кислот (хлороводородной, серной) и тиоцианата аммония на устойчивость расслаивания и соотношение объемов фаз. Область двухфазного жидкого равновесия сохраняется при введении $\mathrm{HCl}$ до 2,5 моль/л, $\mathrm{H}_{2} \mathrm{SO}_{4}-2,0$ моль/л и $\mathrm{NH}_{4} \mathrm{SCN}$ 0,3 моль/л. Изучено межфазное распределение Sc(III), La(III), Ga(III), Fe(III), Tl(III) и Cu(I) в системе $\mathrm{H}_{2} \mathrm{O}$ - Ант - АБСК из хлороводородных растворов. Найдены условия количественного извлечения железа, скандия и таллия. При экстракциии Fe(III), Zn(II), Co(II), Cu(II) и Cd(II) из тиоиианатных растворов установлены оптимальные условия для количественного извлечения ичнка, меди и железа.
\end{abstract}

Ключевые слова: алкилбензолсульфокислота, антипирин, экстракиия, тиоиианаты.

\section{Введение}

Анионные поверхностно-активные вещества находят различное применение в практике аналитической химии, в частности в процессах разделения и концентрирования $[1,2]$. Ocoбый интерес представляют методы экстракции, основанные на расслаивании водных растворов ПАВ при изменении температуры или введении неорганических высаливателей (солей, кислот, оснований) [3-5].

Изучена возможность концентрирования катионов металлов в системах на основе анионогенных ПАВ: бис(алкилполиоксиэтилен)фосфата калия (оксифоса Б) [6, 7], алкилсульфатов и алкилсульфонатов натрия [8], в том числе додецилсульфата натрия [9, 10], триэтаноламиновых солей алкилсульфатов [11], сульфонола [12], алкилбензолсульфокислоты [13]. Расслаивание в

$$
-537-
$$


рассмотренных системах является следствием введения неорганических высаливателей (солей, кислот, оснований) или химического взаимодействия катионных и анионных ПАВ.

При изучении системы вода - алкилбензолсульфокислота - неорганическая кислота установлено, что введение антипирина или диантипирилалкана приводит к образованию второй жидкой фазы в отсутствие неорганической кислоты. Расслаивание в системе является, вероятно, следствием химического взаимодействия компонентов. Это позволяет использовать системы вода - Ант - АБСК в экстракции по аналогии с системами вода - Ант - нафталин2-сульфокислота (НСК) $[14,15]$. В связи с этим представляло интерес изучить возможность применения расслаивающейся системы на основе Ант и АБСК в качестве экстракционной.

\section{Материалы и методы}

В работе использовались:

- Алкилбензолсульфокислота, $\mathrm{C}_{\mathrm{n}} \mathrm{H}_{2 \mathrm{n}+1} \mathrm{C}_{6} \mathrm{H}_{4} \mathrm{SO}_{3} \mathrm{H}$ ( $\left.\mathrm{n}=10-14\right)$. Состав, мас. \%: основное вещество - 96,8, серная кислота - 0,9, несульфированные соединения - 1,8 (ТУ 2481-02605766480-2006).

- Антипирин (2,3-диметил-1-фенил-3-пиразолин-5-он) квалификации ч.д.а. Растворимость при $25{ }^{\circ} \mathrm{C}-57,5$ мас. \% [16].

- Серная кислота, концентрированная ( $\rho=1,832$ г/мл).

- Хлороводородная кислота, концентрированная ( $\rho=1,172$ г/мл).

- Тиоцианат аммония $\mathrm{NH}_{4} \mathrm{SCN}$, ч.д.а.

- Соли металлов - квалификации х.ч. и ч.д.а.

Константу кислотности АБСК определяли потенциометрическим методом при $23{ }^{\circ} \mathrm{C}$ [17]. 50 мл раствора АБСК с концентрацией 0,01 М титровали 0,1 М раствором $\mathrm{NaOH}$. Контроль $\mathrm{pH}$ осуществляли с применением комбинированного электрода ЭСК-10603/7 и pН-метра/иономера Мультитест ИПЛ-101.

Растворимость в системе $\mathrm{H}_{2} \mathrm{O}$ - Ант - АБСК изучена методом изотермического титрования при $(25 \pm 2){ }^{\circ} \mathrm{C}[18]$. Готовили водные растворы АБСК и Ант различной концентрации. Взвешенные количества растворов антипирина титровали $10 \%$-ным раствором АБСК, а растворы АБСК - 30,0 \%-ным раствором Ант. За конечную точку титрования принимали массу титранта, соответствующую образованию устойчивой опалесценции. Титрование повторяли 2-3 раза до получения результатов, отличающихся не более чем на 0,5 мас. \%.

Для изучения фазового состояния системы $\mathrm{H}_{2} \mathrm{O}-$ Ант - АБСК в зависимости от концентрации неорганических кислот в градуированную пробирку вносили 1,0 г Ант, 0,9 г АБСК, соответствующее количество кислоты, доводили объем системы до 10 мл дистиллированной водой и перемешивали. После установления равновесия описывали фазовое состояние и отношение объемов жидких фаз.

Для изучения распределения ионов металлов в градуированные пробирки с притертыми пробками вносили по 1 мл 0,1 моль/л раствора катиона металла, 1,0 г Ант, 0,9 г АБСК, соответствующее количество раствора хлороводородной (или серной кислоты) и, если необходимо, раствор тиоцианата аммония, доводили объем системы до 10 мл дистиллированной водой и перемешивали. После установления равновесия водную фазу отделяли и определяли остаточное содержание ионов металла комплексонометрическим титрованием [19]. 


\section{Обсуждение результатов}

Образование расслаивания в системе $\mathrm{H}_{2} \mathrm{O}$ - Ант - АБСК, очевидно, является результатом протолитического взаимодействия:

$$
\mathrm{L}_{(\mathrm{B})}+\mathrm{RSO}_{3} \mathrm{H}_{(\mathrm{B})}=\mathrm{LH}^{+} \mathrm{RSO}_{3}^{-}(\mathrm{o})
$$

где $\mathrm{L}$ - Ант; $\mathrm{RSO}_{3}$ - алкилбензолсульфонат-ион.

Экспериментально определенное значение константы кислотности АБСК составило $6,76 \cdot 10^{-3}\left(\mathrm{pK}_{\mathrm{a}}=2,17 \pm 0,19\right)$, что подтверждает возможность участия АБСК в представленном процессе в качестве кислотного компонента.

Для оптимизации концентрационных параметров экстракции определена верхняя граница области расслаивания в системе $\mathrm{H}_{2} \mathrm{O}-$ Ант - АБСК при $(23 \pm 2)^{\circ} \mathrm{C}$ (рис. 1). Исследованная система является условно трёхкомпонентной, так как используемый ПАВ представляет собой смесь гомологов. Расслаивание существует при достаточном избытке АБСК, увеличение содержание Ант приводит к гомогенизации системы. Отмечено, что с ростом концентрации антипирина уменьшается вязкость фаз и увеличивается их подвижность. Расслаивание в системе существует при суммарном содержании компонентов (Ант и АБСК) более 4,0 мас. \%, что позволяет осуществлять экстракцию из достаточно разбавленных растворов.

На основании полученных данных определены оптимальные концентрационные параметры осуществления экстракции: $\mathrm{m}_{\text {Ант }}=1,0$ г, $\mathrm{m}_{\text {АБск }}=0,9$ г, вода до 10,0 мл. Органическая фаза расположена внизу, прозрачная и имеет желтую окраску, ее объем составляет 1,7 мл. Равновесное значение $\mathrm{pH}$ водной фазы 1,96 .

При оптимальных соотношениях компонентов изучено влияние неорганических кислот $\left(\mathrm{H}_{2} \mathrm{SO}_{4}\right.$ и $\left.\mathrm{HCl}\right)$ на фазовое состояние системы. Установлено, что область двухфазного жидкого равновесия существует до 2,0 моль/л серной и 2,5 моль/л хлороводородной кислот. Введение

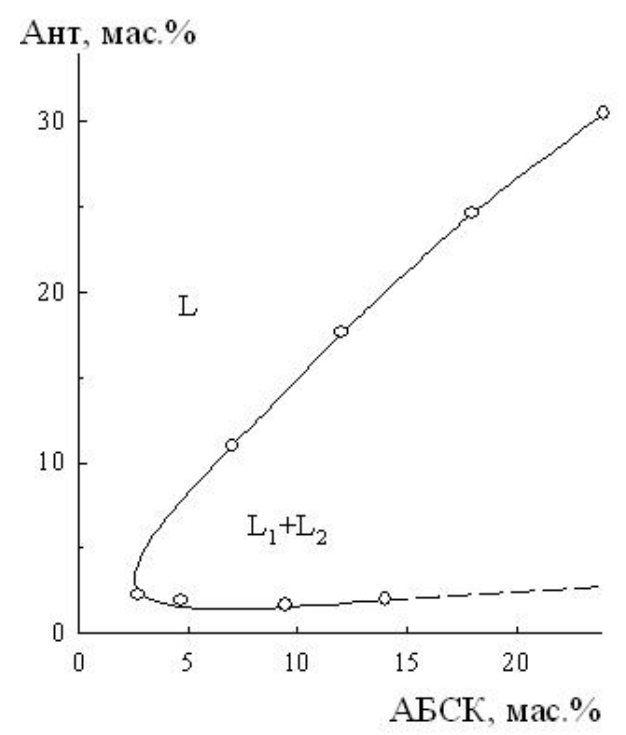

Рис. 1. Граница области расслаивания системы $\mathrm{H}_{2} \mathrm{O}-$ Ант - АБСК при $(23 \pm 2){ }^{\circ} \mathrm{C}$

Fig. 1. The boundary of the delamination region in system $\mathrm{H}_{2} \mathrm{O}-\mathrm{Ant}-\mathrm{ABSA}$ at $(23 \pm 2){ }^{\circ} \mathrm{C}$ 
кислот приводит к небольшому увеличению объема органической фазы: до 1,8 мл в системе с $\mathrm{H}_{2} \mathrm{SO}_{4}$ и до 2,0 мл в системе с $\mathrm{HCl}$. При концентрации серной кислоты более 2,0 моль/л из-за увеличения плотности водной фазы происходит инверсия фаз. Увеличение концентрации кислот до 3,0 моль/л вызывает появление твердой фазы, образованной, вероятно, АБСК.

Для оценки экстракционных возможностей системы $\mathrm{H}_{2} \mathrm{O}$ - Ант - АБСК исследовано распределение 0,01 моль/л растворов ионов металлов, образующих с Ант различные виды комплексов: координационные ( $\mathrm{Sc}(\mathrm{III})$ и $\mathrm{La}(\mathrm{III}))$, ионные ассоциаты (Cu(I), $\mathrm{Fe}(\mathrm{III}), \mathrm{Ga}(\mathrm{III}), \mathrm{Tl}(\mathrm{III})$ ), в зависимости от концентрации хлороводородной кислоты.

Как видно на рис. 2, при отсутствии $\mathrm{HCl}$ наблюдается количественная экстракция (>99 \%) скандия, на 92 \% извлекается лантан. Их извлечение можно объяснить образованием катионных комплексов с антипирином:

$$
\mathrm{M}_{(\mathrm{B})}^{\mathrm{n+}}+\mathrm{mL}_{(\mathrm{B})}+\mathrm{nRSO}_{3(\mathrm{~B})}^{-}=\left[\mathrm{ML}_{\mathrm{m}}\right]\left(\mathrm{RSO}_{3}\right)_{\mathrm{n}(\mathrm{o})},
$$

где $\mathrm{L}$ - Ант; $\mathrm{RSO}_{3}$ - алкилбензолсульфонат-ион.

C ростом кислотности комплексы разрушаются вследствие протонирования реагента, что приводит к уменьшению степени извлечения.

В широком интервале концентраций хлороводородной кислоты (0,1-2,5 моль/л) наблюдается количественное извлечение ионов таллия в виде тетрахлороталлат-иона. Предполагаемый механизм экстракции Tl(III) можно изобразить следующим уравнением:

$$
\left[\mathrm{TlCl}_{4}\right]_{(\mathrm{B})}^{-}+\mathrm{LH} \cdot \mathrm{SO}_{3} \mathrm{R}_{(\mathrm{o})}=\mathrm{LH} \cdot\left[\mathrm{TlCl}_{4}\right]_{(\mathrm{o})}+\mathrm{RSO}_{3}^{-}(\mathrm{B})
$$

где $\mathrm{L}$ - Ант, $\mathrm{RSO}_{3}$ - алкилбензолсульфонат-ион.

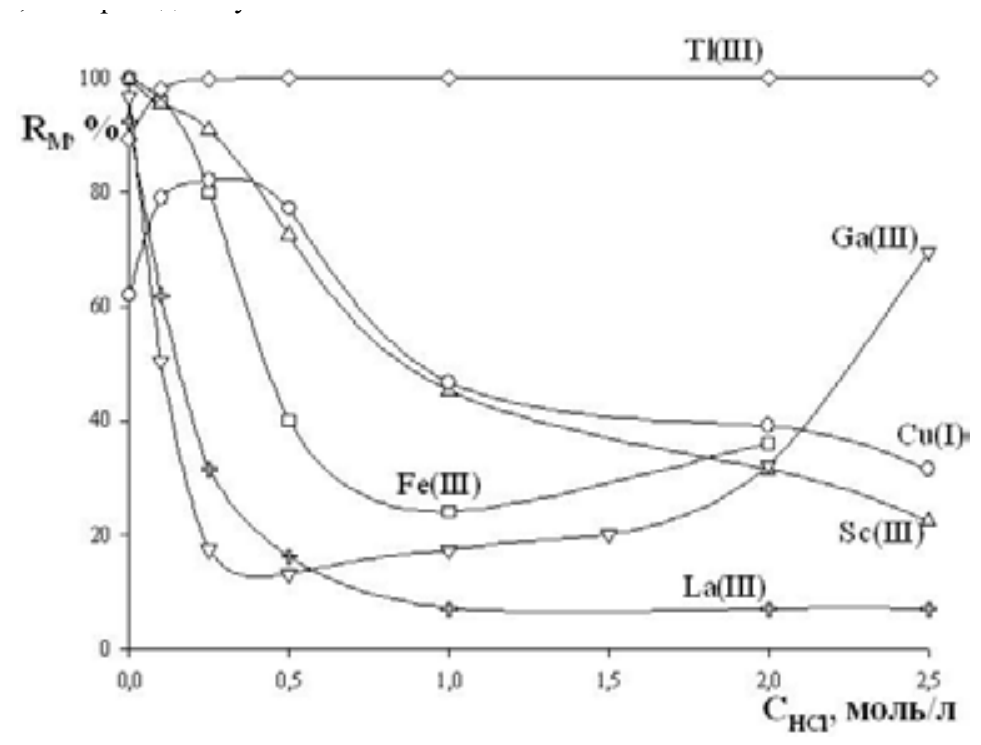

Рис. 2. Распределение $1 \cdot 10^{-4}$ моль ионов металлов в системе вода - Ант - АБСК в зависимости от концентрации $\mathrm{HCl}$

Fig. 2. Distribution of $1 \cdot 10^{-4} \mathrm{~mol}$ of metal ions in system $\mathrm{H}_{2} \mathrm{O}-\mathrm{Ant}-\mathrm{ABSA}$ depending on the $\mathrm{HCl}$ concentration 
Кривая извлечения меди(I) проходит через максимум $\left(\mathrm{R}_{\max }=82 \%\right)$, с ростом кислотности происходит частичное окисление меди(I), в результате чего степень ее извлечения падает. Количественная экстракция железа(III) и галлия возможна лишь по координационному механизму при отсутствии неорганической кислоты в системе. Для экстракции хлоридных ацидокомплексов $\mathrm{Fe}(\mathrm{III})$ и $\mathrm{Ga}(\mathrm{III})$ требуется концентрация $\mathrm{HCl}$ выше 2,5 моль/л.

Полученный вид кривых распределения подобен кривым извлечения металлов из хлороводородных растворов в системе вода - Ант - НСК [14]. Это позволяет сделать вывод о схожести механизмов расслаивания и экстракции. Антипирин выполняет роль экстрагента. При экстракции по координационному механизму АБСК и НСК выступают в качестве противоионов, в случае извлечения ацидокомплексов ионов металлов - в качестве фазообразователей. Следует заметить, что в системах с НСК интервал кислотности, в котором сохраняется расслаивание, шире, чем в системе с АБСК, и ограничен 4,0 моль/л $\mathrm{HCl}$. При этом АБСК является доступным и достаточно дешевым реагентом, производимым в больших количествах, в сравнении с труднодоступной НСК.

Литературные данные по экстракции ионов металлов хлороформными растворами производных пиразолона [20] свидетельствуют, что максимальное число ионов металлов извлекается из тиоцианатных растворов. В связи с этим представляло интерес рассмотреть закономерности экстракции некоторых ионов металлов из тиоцианатных растворов в системе $\mathrm{H}_{2} \mathrm{O}$ - Ант - АБСК.

Экстракцию тиоцианатных комплексов металлов, как правило, проводят из слабокислых растворов. Для исключения конкуренции с хлоридными ацидокомплексами исследуемых металлов распределение изучали в сернокислых растворах.

На рис. 3 представлены результаты изучения распределения тиоцианатных комплексов ионов железа, кобальта, меди (II), кадмия и цинка от концентрации $\mathrm{NH}_{4} \mathrm{SCN}$ при постоянной концентрации серной кислоты 0,5 моль/л.

При отсутствии тиоцианата извлечение металлов не превышает $40 \%$. Количественное извлечение $\mathrm{Fe}(\mathrm{III}), \mathrm{Cu}(\mathrm{II}), \mathrm{Zn}(\mathrm{II})$ достигается при концентрации [ $\left.\mathrm{SCN}^{-}\right]-$-ионов от 0,1 моль/л, для экстракции тиоцианатного комплекса кобальта требуется более высокая концентрация $\mathrm{NH}_{4} \mathrm{SCN}-0,3$ моль/л, экстракция кадмия с увеличением содержания [ $\left.\mathrm{SCN}^{-}\right]$растет, но остается неколичественной.

Изучение распределения ионов металлов из тиоцианатных растворов от концентрации серной кислоты проводили при концентрации $\mathrm{NH}_{4} \mathrm{SCN}$ 0,1 моль/л. Как видно на рис. 4, максимальное извлечение ионов металлов наблюдается при отсутствии серной кислоты в системе. Ее введение приводит к появлению осадков, незначительному уменьшению степени извлечения железа (III) и цинка и существенному падению кривых распределения кобальта и кадмия, для количественного извлечения которых требуется более высокая концентрация [ $\left.\mathrm{SCN}^{-}\right]$-ионов.

\section{Заключение}

Полученные результаты позволяют сделать вывод, что расслаивающаяся система на основе антипирина и алкилбензолсульфокислоты может быть использована в качестве экстракционной. Область расслаивания системы $\mathrm{H}_{2} \mathrm{O}$ - Ант - АБСК устойчива к действию неорганических кислот и сохраняется в интервале от $\mathrm{pH} 1,96$ до 2 моль/л серной и 2,5 моль/л хлороводородной

$$
-541-
$$




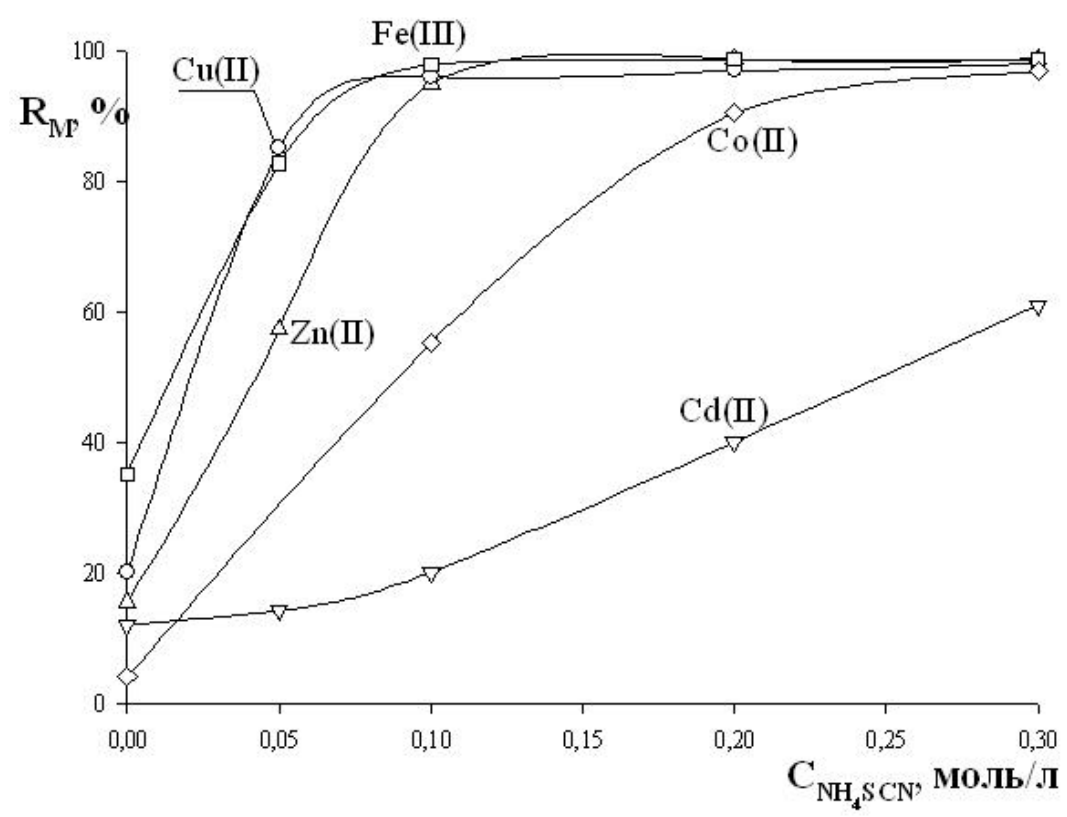

Рис. 3. Распределение $1 \cdot 10^{-4}$ моль ионов металлов в системе: $\mathrm{H}_{2} \mathrm{O}-$ Ант - АБСК $-0,5$ моль/л $\mathrm{H}_{2} \mathrm{SO}_{4}$ в зависимости от концентрации $\mathrm{NH}_{4} \mathrm{SCN}$

Fig. 3. Distribution of $1 \cdot 10^{-4} \mathrm{~mol}$ of metal ions in the system: $\mathrm{H}_{2} \mathrm{O}-\mathrm{Ant}-\mathrm{ABSA}-0.5 \mathrm{~mol} / 1 \mathrm{H}_{2} \mathrm{SO}_{4}$ depending on the $\mathrm{NH}_{4} \mathrm{SCN}$ concentration

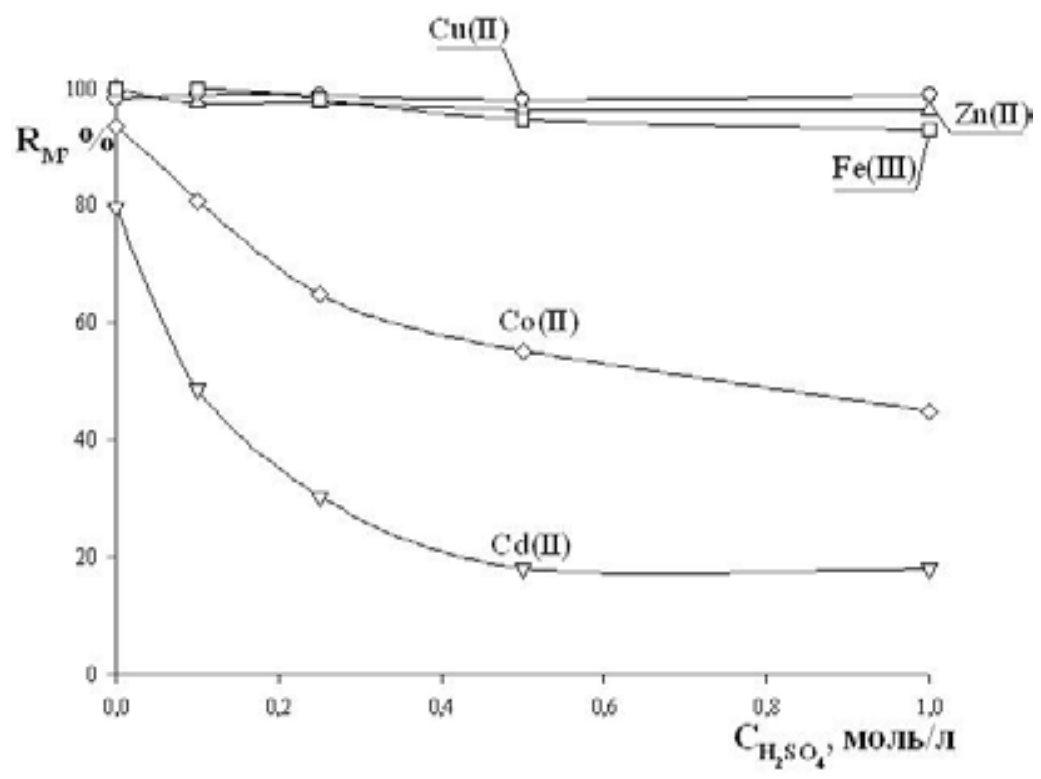

Рис. 4. Распределение $1 \cdot 10^{-4}$ моль ионов металлов в системе: $\mathrm{H}_{2} \mathrm{O}-$ Ант - АБСК - 0,1 моль/л $\mathrm{NH}_{4} \mathrm{SCN}_{\text {в }}$ зависимости от концентрации $\mathrm{H}_{2} \mathrm{SO}_{4}$

Fig. 4. Distribution of $1 \cdot 10^{-4} \mathrm{~mol}$ of metal ions in the system: $\mathrm{H}_{2} \mathrm{O}-\mathrm{Ant}-\mathrm{ABSA}-0.1 \mathrm{~mol} / 1 \mathrm{NH}_{4} \mathrm{SCN}$ depending on the $\mathrm{H}_{2} \mathrm{SO}_{4}$ concentration 
кислот. В отсутствие неорганических кислот в системе возможно количественное извлечение железа(III), галлия, скандия и лантана. Из хлороводородных растворов количественно экстрагируется таллий(III).

Введение тиоцианата аммония позволяет расширить ассортимент извлекающихся металлов. Создается возможность количественного извлечения меди(ІІ), железа(ІІІ), цинка и кобальта.

Преимуществом изученной системы является повышение безопасности труда и удешевление процесса за счет исключения из него органических растворителей и использования выпускаемой в промышленных масштабах и недорогой АБСК.

\section{Список литературы}

1. Shtykov S.N. Surfactants in analysis: progress and development trends. Journal of Analytical Chemistry 2000. Vol. 55(7), P. 608-614.

2. Paleologos E.K. Surfactant-Mediated Extraction Techniques. The Application of Green Solvents in Separation Processes. Elsevier 2017. P. 349-375.

3. Ojeda C.B., Rojas F.S. Separation and preconcentration by cloud point extraction procedures for determination of ions: recent trends and applications. Microchimica Acta 2012. Vol. 177 (1-2), P. $1-21$.

4. Леснов А.Е., Денисова С.А. Гель-экстракция поверхностно-активными веществами. Вестник Пермского университета. Серия Химия 2014. Вып. 1 (13). C. 79-93. [Lesnov A.E., Denisova S.A. Surfactant gel extraction. Perm University Bulletin. Chemistry 2014. №1(13), P. 79-93. (In Russ.)].

5. ElokhovA.M.,LesnovA.E.,KudryashovaO.S.Saltingoutofpotassiumbis(alkylpolyoxyethylene) phosphate with ammonium salts as the base of micellar extraction processes development. Russian Journal of General Chemistry 2015. Vol. 85(11). P. 2657-2662.

6. Kudryashova O.S., Mokhnatkina N.N., Denisova S.A., Lesnov A.E. Phase equilibria in water - alkali metal (ammonium) sulfate - oxifos B systems. Russian Journal of Inorganic Chemistry 2010. Vol. 55(10), P. 1617-1619.

7. Леснов А.Е., Денисова С.А., Чухланцева Е.Ю., Заболотных С.А., Останина Н.Н. Гельэкстракция тиоцианатных комплексов металлов в расслаивающихся системах «вода - катамин АБ - хлорид калия» и «вода - оксифос Б - сульфат аммония». Химия в интересах устойчивого развития 2015. T. 23 (4). C. 361-366. [Lesnov A.E., Denisova S.A., Chukhlanceva E.Yu., Zabolotnykh S.A., Ostanina N.N. Gel Extraction of Thiocyanate Complexes of Metals in Layering Systems "Water Catamine AB - Potassium Chloride" and "Water - Oxyphos B - Ammonium Sulphate". Chemistry for Sustainable Development 2015.Vol. 23(4), P. 361-366. (In Russ.)].

8. Goryacheva I.Yu., Loginov A.S., Lavrova T.N., Popov M.A. Extraction preconcentration with anionic surfactants in acidic solutions. Journal of Analytical Chemistry 2007. Vol. 62 (5), P. 411-415.

9. Daia C., Liua Y., Wanga Sh. Investigation on the phase behaviors of aqueous surfactant two-phase systems in a mixture of N-dodecyl-N-methylpiperidinium brmide $\left(\mathrm{C}_{12} \mathrm{MDB}\right)$ and sodium dodecyl sulfate (SDS). Colloids and Surfaces A: Physicochemical and Engineering Aspects 2015. Vol. 468. P. 322-326.

$$
-543-
$$


10. Tagashira S., Ichimaru T., Nozaki K., Murakami Y.Surfactant gel extraction of metal amminecomplexes using SDS and $\mathrm{KCl}$ at room temperature end a small-angle X-ray diffraction study of the surfactant phase. Solvent extraction Research and Development. Japan. 2013. Vol. 20, P. 39-52.

11. Леснов А.Е., Кудряшова О.С., Денисова С.А. Фазовые и экстракционные равновесия в системах вода - алкилсульфаты или алкилсульфонаты - неорганический высаливатель. Вестник Пермского университета. Серия Химия. 2011. Вып. 1 (1). C. 71-75. [Lesnov A.E., Kudryashova O.S., Denisova S.A. Phase and extraction equilibrium in the systems of water - alkyl sulphates or alkyl sulphonates - inorganic salting-out component. Perm University Bulletin. Chemistry 2011. № 1(1), P. 71-75. (In Russ.)].

12. Zabolotnykh S.A., Lesnov A.E., Denisova S.A. Phase and extraction equilibria in $\mathrm{H}_{2} \mathrm{O}-$ sulfonol $-\mathrm{HCl}\left(\mathrm{H}_{2} \mathrm{SO}_{4}\right)$ and $\mathrm{H}_{2} \mathrm{O}$ - sodium dodecyl sulfate- $\mathrm{HCl}\left(\mathrm{H}_{2} \mathrm{SO}_{4}\right)$ systems. Russian Journal of Physical Chemistry A 2016. Vol. 90 (10), P. 1942-1947.

13. Заболотных С.А., Леснов А.Е., Денисова С.А. Гель-экстракция ионов металлов диантипирилалканами в водных расслаивающихся системах на основе алкилбензолсульфокислоты. Вода: Химия и экология 2017. № 1. С. 73-79. [Zabolotnykh S.A., Lesnov A.E., Denisova S.A. Gel extraction of metal ions using dianthapyrylium alkanes in stratified water systems based on alkyl benzene sulfonic acid. Water: chemistry and ecology 2017. № 1, P. 73-79. (In Russ.)].

14. Петров Б.И., Денисова С.А., Леснов А.Е., Шестакова Г.Е.. Межфазное распределение некоторых элементов в системе вода - антипирин - нафталин-2-сульфокислота. Известия вузов. Химия и химическая технология 1999. Т. 42(1), C. 21-23. [Petrov B.I., Denisova S.A., Lesnov A.E., Shestakova G.E. Interphase distribution of some elements in the water - antipyrine naphthalene-2-sulfonic acid system. Chemistry and chemical technology 1999. Vol. 42(1), P. 21-23. (In Puss.)].

15. Petrov B.I., Lesnov A.E., Denisova S.A. Phase and extraction equilibriums in aqueous segregable systems with protolytic interaction. Journal of Analytical Chemistry 2015. Vol. 70(6), P. 647-660.

16. Denisova S.A., Kudryashova O.S., Lesnov A.E., Sazonova E.A. Phase and extraction equilibria in the antipirin - pyrocatechol - water system. Russian Journal of General Chemistry 2007. T. 77(11), Р. $1855-1858$.

17. Инцеди Я. Применение комплексов в аналитической химии. Перевод с английского О.М. Петрухина и. Б.Я. Спивакова М.: Мир, 1979. 376 с. [Inczedy J. Application of complexes in analytical chemistry. Translated from English by O.M. Petrukhin and B.Ya. Spivakova. Moscow: Mir, 1979. 376 p. (In Puss.)].

18. Ulloa G., Coutens C., Sánchez M., Sineiro J., Rodríguez A., Deive F.J., Núñez M.J. Sodium salt effect on aqueous solutions containing Tween 20 and Triton X-102G. The Journal of Chemical Thermodynamics 2012. Vol. 47. P. 62-67.

19. Шварценбах Г., Флашка Г. Комплексонометрическое титрование. Перевод с немецкого Ю.И. Вайнштейн. М.: Химия, 1970. 360 с. [Schwarzenbach G., Flachka G. Complexometric titration. Translation from German by Yu.I. Weinstein. Moscow: Chemistry, 1970. 360 p. (In Puss.)].

20. Петров Б.И. Диантипирилметаны как аналитические реагенты. Журнал аналитической химии 1983. Т. 38(11), С. 2051-2076. [Petrov B.I. Diantipyrylmethanes as analytical reagents. Journal of Analytical Chemistry 1983. Vol. 38(11), P. 2051-2076. (In Russ.)]. 